\title{
Current Protection Applicability Analysis of Flexible DC Power Supply Network
}

\author{
Yuan $\mathrm{GAO}^{1}$, Bingyuan YANG and Dongsheng LI \\ Electric Power College, Inner Mongolia University of Technology, Hohhot 010080, \\ China
}

\begin{abstract}
In the flexible AC/DC distribution system supplying passive network, when the modular multi-level converter (MMC) inverter AC line fault occurs, the MMC short-circuit current amplitude is greatly affected by the control strategy, which may affect the operation performance of three-stage current protection. In view of this, a flexible AC/DC distribution network system supplying power to the passive network is built on the RTDS platform, and then the AC fault traverse strategy is designed in the MMC controller. Based on the thinking of coordinated control and protection of the fault through the strategy into two cases with no input to higher current protections performance simulation contrast, the simulation results show that asymmetric fault occurred when MMC inverter AC line, under the effect of communication failure through the strategy, the current main protection I, II period of refusing action, only by this line nearly backup protection current section III delay removal of fault. The three-stage current protection based on the fault current characteristics of pure $\mathrm{AC}$ system has poor action performance and is no longer suitable for the AC line of MMC inverter station.
\end{abstract}

Keywords. AC/DC hybrid distribution network, power supply network, backup protection

\section{Introduction}

The construction of flexible AC/DC hybrid distribution network is one of the important directions for the development and reform of distribution network in the future. Flexible AC/DC hybrid distribution network is composed of converter station, distributed energy, AC/DC load, etc. its converter adopts modular multilevel converter (MMC), which is the core equipment to realize the interconnection of AC/DC system. MMC has no commutation failure, can supply power to passive network suitable for wind farm grid connection, isolated island, urban center and other application scenarios, and can independently adjust active and reactive power. It has incomparable advantages compared with other converters [1-2].

The research on flexible AC-DC distribution network focuses on fault characteristics, AC-DC interaction mechanism, improved control strategy, short-circuit current characteristics of flexible DC system and so on. The fault characteristics are closely related to the control strategy of the flexible direct current system. The control strategy of the flexible direct current system supplying power to the passive network is different from the control strategy of the flexible direct current system connecting the

1 Corresponding Author, Yuan GAO, Electric Power College, Inner Mongolia University of Technology, Hohhot 010080, China, Email: 1209099145@qq.com. 
active network at both ends. Reference [3] analyzes the discharge mechanism of MMC capacitor when the $\mathrm{AC}$ system at the sending end of the flexible direct current transmission system supplying power to the passive network fails, points out that the unbalanced power transmission will make the DC voltage of MMC-HVDC system drop seriously, and then designs a control strategy which can contain the DC voltage drop when the $\mathrm{AC}$ system at the sending end fails. Because the flexible AC / DC distribution network contains large-scale power electronic devices, its ability to withstand over-current is weak, and the fault current may reach the self-protection threshold of power electronic devices in a very short time after a fault occurs. Therefore, it is necessary to use the improved control strategy for fault current active control to reduce the fault current amplitude and realize fault ride through. In reference [4], aiming at the negative sequence current caused by unbalanced grid voltage or asymmetric AC system fault, an AC fault ride through strategy suitable for MMCHVDC system supplying power to passive network is proposed, and a positive and negative sequence passive controller using El model is designed. In references [5-9], the mathematical model and calculation method of short-circuit current of flexible HVDC system in case of AC fault in MMC converter station are proposed. Through the analysis of the short-circuit current characteristics of the flexible direct current system, it can establish foundations for the control and protection research of the flexible direct current system connected to the AC system in the future.

Protection technology is one of the key contents of flexible AC / DC distribution network research. The traditional AC distribution network line relay protection based on the configuration and setting of fault characteristics of pure AC system does not consider the impact of flexible DC system access on the electrical characteristics of AC distribution network protection, which can lead to the reduction of relay protection operation reliability. However, there are few researches on the protection technology of AC/DC hybrid distribution network supplying power to passive network. In view of this, this paper analyzes the applicability of three-stage current protection for AC line of $\mathrm{MMC}$ inverter station supplying flexible $\mathrm{AC} / \mathrm{DC}$ distribution network to passive network.

According to the principle of phase locked loop (DDSRF-PLL) of positive and negative sequence decoupling technology of double synchronous rotating coordinate transformation, positive and negative sequence active controller and negative sequence passive controller is designed respectively based on MMC inner loop current controller to realize MMC AC fault ride through strategy. Then, a flexible AC/DC distribution network model which supplies power to the passive network is built on the RTDS simulation platform, and the fault characteristics of the inverter side AC system are simulated and analyzed. Finally, with the help of the derived short-circuit current characteristics of $\mathrm{MMC}$, the influence of the fault ride through strategy on the operation performance of the three-stage current protection is simulated and compared with that of the non fault ride through strategy.

\section{AC/DC Hybrid Distribution Network System Model}

\subsection{System Description}

The structure of AC/DC hybrid distribution network supplying power to passive network is shown in figure 1 . The sending end active system is represented by infinite 
power supply, and the receiving end passive network is simulated by constant power AC load model. The bus voltage of sending end active system and receiving end passive system is $U_{S}$ and $U_{L}$ respectively, and the output voltage of MMC1 rectifier station and MMC2 inverter station is $U_{V 1}$ and $U_{V 2}$ respectively. The bipolar DC voltage between poles of MMC-HVDC is $U_{d c}$, and the DC current is $I_{d c}$. The positive direction of power transmission of the system is shown by the arrow in figure 1 .

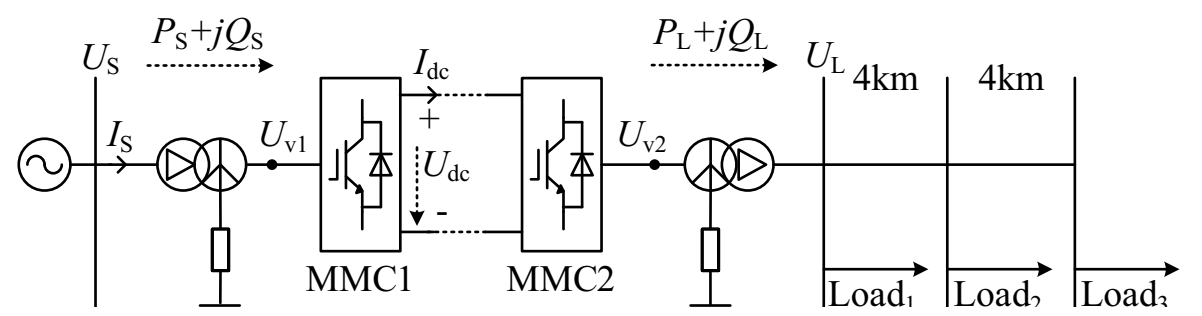

Figure 1. AC/DC hybrid distribution system structure.

\subsection{Structure of $M M C$ Converter}

The bridge arm of modular multilevel converter (MMC) is not composed of multiple switching devices directly in series, but adopts the way of sub module cascade. The structure of MMC is shown in figure 2 below, which is composed of three-phase six leg bridge. The upper and lower leg bridge in the same phase constitute a phase unit, and each leg bridge is composed of a series reactor $L_{s}$ and $N_{s m}$ sub modules in series. Each sub module SM is composed of two insulated gate bipolar transistors (IGBT) T1 and T2 with reverse parallel diodes D1 and D2. The $\mathrm{H}$ half bridge is composed of one capacitor in parallel.

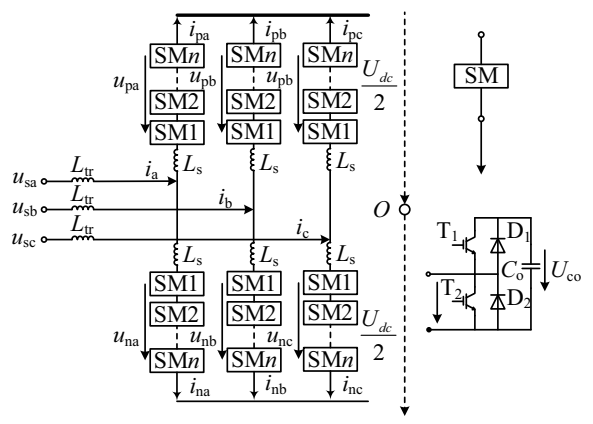

Figure 2. MMC structural diagram.

The sub module widely used in MMC converter is half bridge sub module, its main disadvantage is that when the DC side fails, the continuous current of the parallel diode provides a path for the DC fault current, which leads to the failure isolation of DC side even if IGBT is off, and the DC side fault cannot be effectively isolated, and the fault isolation must be realized through DC breaker [10]. 


\section{Control Strategy of MMC-HVDC System}

\subsection{Steady State Control Strategy of MMC-HVDC System}

The rectifier station MMC1 connected with the active network adopts the control strategy of constant DC voltage and constant reactive power to maintain the voltage level and active power balance of the whole DC network. The inverter MMC2 connected to the passive $\mathrm{AC}$ network adopts the control strategy of constant $\mathrm{AC}$ voltage amplitude and constant AC frequency.

MMC controller adopts double closed-loop control. In DQ synchronous coordinate system, MMC control strategy contains outer loop controller and inner loop current controller. The outer loop controller outputs the command value $i_{v d}^{*}$ of active current and the command value $i_{v q}^{*}$ of reactive current. The inner loop current controller makes $d q$ axis current track its command value $i_{v d}^{*}$ and $i_{v q}^{*}$ quickly.

\subsubsection{Outer Loop Controller of Rectifier Station}

The DC is set by the $U_{d c}^{*}$ voltage controller and the output is $i_{v d}^{*}$ Its controller is shown in figure 3. The output of the controller is $i_{v q}^{*}$ when $Q_{s}^{*}$ is given by the fixed reactive power controller. Its controller is shown in figure 4. Among them, the $i_{v d}^{*}$ instruction value and $i_{v q}^{*}$ instruction value are added with limiting link.

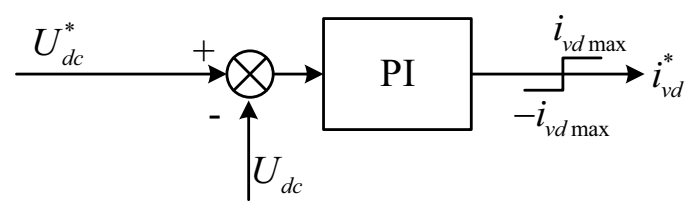

Figure 3. Constant DC voltage controller.

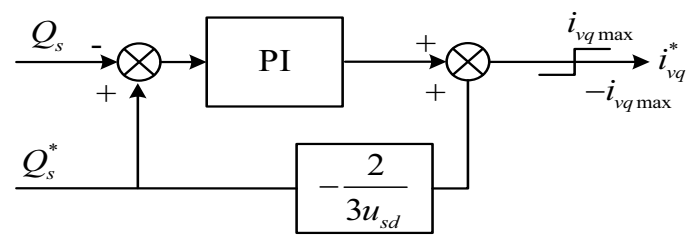

Figure 4. Constant reactive power controller.

\subsubsection{Outer Loop Controller of Inverter Station}

Current vector controller has the advantages of fast current response and can control AC fault current, which is suitable for practical engineering, so MMC2 adopts current vector controller.

Phase locked loop (PLL) is not needed for MMC2 controller, because the frequency of receiving power grid is a given value $f_{0}=50 \mathrm{HZ}$, that is, the electric angle is determined by $\theta=\omega_{0} t$. The purpose of the controller is to make $u_{s d}{ }^{*}=U_{s m}$ 
(bus voltage amplitude of passive AC network) and ${u_{s q}}^{*}=0$, output as valve side active current command value $i_{v d}^{*}$ and reactive active current command value $i_{v q}^{*}$. The $i_{v d}^{*}$ and $i_{v q}^{*}$ instruction values are added with limiting link. Its controller is shown in figure 5.
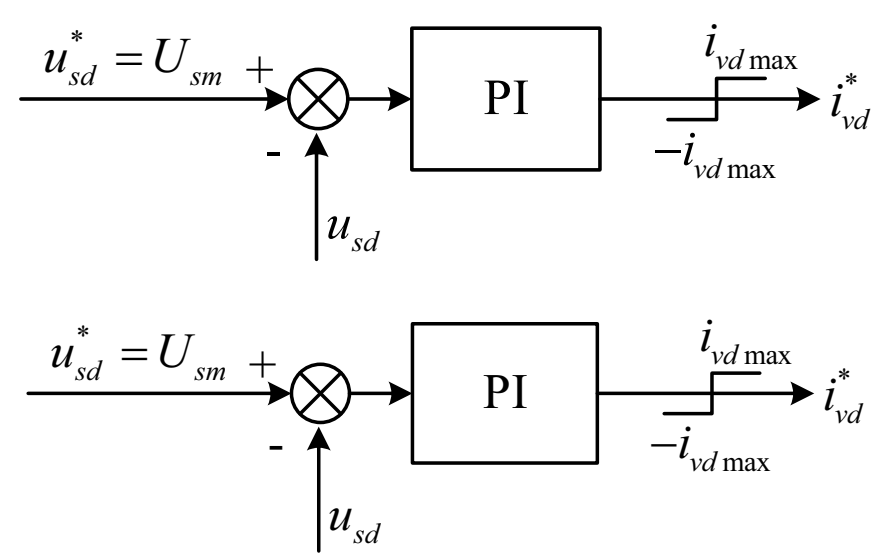

Figure 5. Constant AC voltage amplitude controller.

\subsubsection{Inner Loop Current Controller}

$i_{d}$ and $i_{q}$ are state variables, $u_{d}$ and $u_{q}$ are interference signals, $v_{d}^{*}$ and $v_{\mathrm{q}}^{*}$ are control inputs. $v_{d}^{*}$ and $v_{\mathrm{q}}^{*}$ are controlled by the negative feedback of state variables $i_{d}$ and $i_{q}$, so that $i_{d}$ and $i_{q}$ can quickly track their instruction values $i_{v d}^{*}$ and $i_{v q}^{*}$. The modulated signal can be obtained by inverse transformation of $v_{d}^{*}$ and $v_{\mathrm{q}}^{*}[11]$. Its controller is shown in figure 6 . The control input is selected as follows:

$$
\begin{aligned}
& v_{d}^{*}=u_{d}+\omega L i_{q}-\left[k_{p 1}\left(i_{v d}^{*}-i_{d}\right)+k_{i 1} \int\left(i_{v d}^{*}-i_{d}\right) d t\right] \\
& v_{q}^{*}=u_{q}-\omega L i_{d}-\left[k_{p 2}\left(i_{v q}^{*}-i_{q}\right)+k_{i 2} \int\left(i_{v q}^{*}-i_{q}\right) d t\right]
\end{aligned}
$$

In the formula, the first two terms are feedforward compensation, including interference signal and $d q$ axis coupling term, and the third term is state variable $P I$ negative feedback regulation term.

Selected inner loop current command value:

$$
\begin{gathered}
i_{v d}^{*}=k_{p 3}\left(U_{d c}^{*}-U_{d c}\right)+k_{i 3} \int\left(U_{d c}^{*}-U_{d c}\right) d t \\
i_{v q}^{*}=\frac{-Q^{*}}{1.5 u_{d}}+k_{p 4}\left(Q-Q^{*}\right)+k_{i 4} \int\left(Q-Q^{*}\right) d t
\end{gathered}
$$




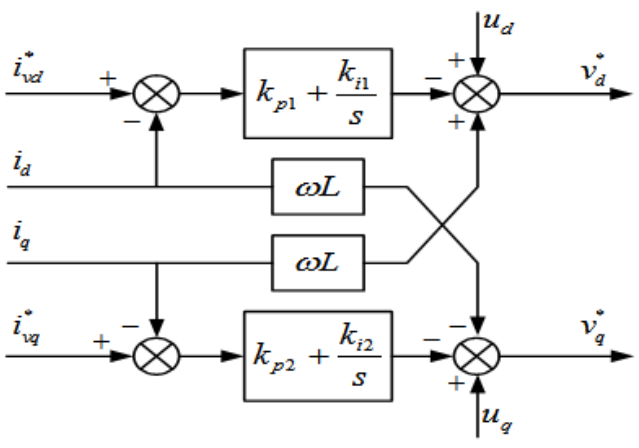

Figure 6. Inner loop current controller.

\subsubsection{Fault Crossing Strategy of MMC HVDC System}

Whether it is an active network connected to $\mathrm{MMC1}$ or a passive network connected to MMC2, it is likely that the three-phase imbalance occurs, and the AC power grid asymmetric failure occurs [12].

The control goal of fault crossing strategy is to suppress the negative sequence current on valve side in case of three-phase unbalance and asymmetric fault of AC system. Both the rectifier station MMC1 and the inverter station MMC2 are equipped with the internal loop current positive and negative sequence controllers. The internal loop current positive and negative sequence controllers use the phase locked loop DDSRF-PLL based on the double synchronous rotation coordinate transformation to remove the negative sequence fundamental wave components, and set the negative sequence active current command value and the reactive current instruction value to 0 ; The positive sequence active current command value and the reactive current instruction value are given by the original outer loop controller.

The instantaneous symmetrical component method [13] is introduced to decompose the instantaneous positive sequence component and negative sequence component of the grid voltage and the instantaneous positive sequence component and negative sequence component of the valve side current. Control relationship of positive and negative sequence controller:

$$
\begin{aligned}
& v_{d}^{+^{*}}=u_{d}^{+}+\omega L i_{q}^{+}-\left[i_{v d}^{+^{*}}-i_{d}^{+}\right]\left(k_{p 1}^{\prime}+\frac{k_{i 1}^{\prime}}{s}\right) \\
& v_{q}^{+^{*}}=u_{q}^{+}-\omega L i_{d}^{+}-\left[i_{v q}^{+^{*}}-i_{q}^{+}\right]\left(k_{p 2}^{\prime}+\frac{k_{i 2}^{\prime}}{s}\right) \\
& v_{d}^{-*}=u_{d}^{-}+\omega L i_{q}^{-}-\left[i_{v d}^{-^{*}}-i_{d}^{-}\right]\left(k_{p 1}^{\prime \prime}+\frac{k_{i 1}^{\prime \prime}}{s}\right) \\
& v_{q}^{-*}=u_{q}^{-}-\omega L i_{d}^{-}-\left[i_{v q}^{-^{*}}-i_{q}^{-}\right]\left(k_{p 2}^{\prime \prime}+\frac{k_{i 2}^{\prime \prime}}{s}\right)
\end{aligned}
$$


where $u_{d}^{+}, u_{q}^{+}$and $u_{d}^{-}, u_{q}^{-}$are $d q$ axis components obtained by forward synchronous rotation coordinate transformation and reverse synchronous rotation coordinate transformation for $u_{s \alpha}$ and $u_{s \beta}$ in two-phase $\alpha \beta$ static coordinate system respectively.

The principle block diagram of inner loop positive and negative sequence current controller is shown in figure 7.
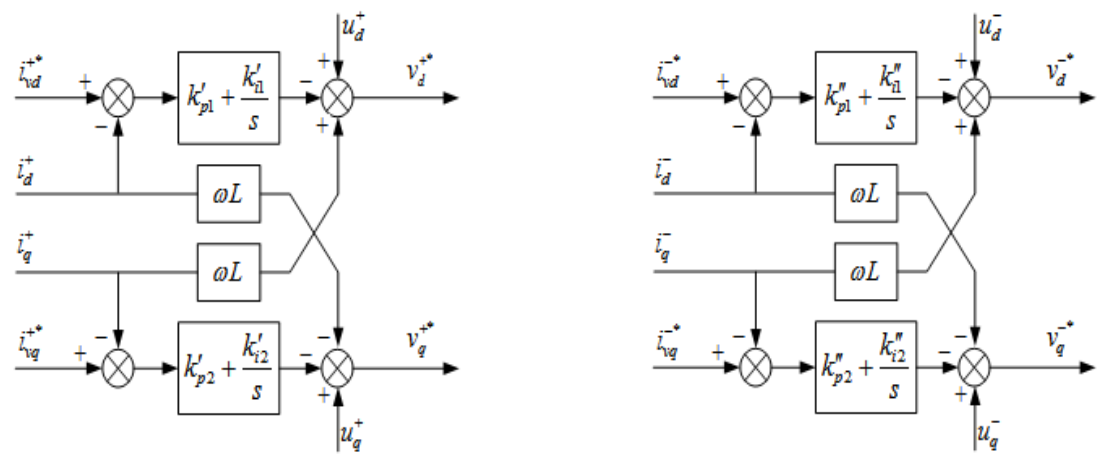

Figure 7. Internal loop positive and negative sequence current controller.

In positive and negative sequence active controller, electrical angle $\theta=\omega t$ is needed for forward synchronous rotation coordinate transformation and reverse synchronous rotation coordinate transformation, which represents the synchronous phase of external AC power grid obtained by phase locked loop (PLL). The design principle of the positive and negative sequence passive controller is similar to that of the positive and negative sequence active controller. The difference is that the positive and negative sequence passive controller has no phase locked loop (PLL). The phase angle needed for the valve side current transformation is given by $\theta=\omega_{0} t$ and $f_{0}=50 \mathrm{HZ}$, while the phase angle needed for the network side voltage is given by $\theta=\omega_{0} t-30^{\circ}$ (when the converter transformer is connected with DYn, positive sequence current phase and triangle side lag Star side is 30 degrees; The negative sequence current phase is 30 , and the triangle side is 30 degrees ahead of the star side.

\section{Applicability Analysis of Three-Stage Current Protection}

When the AC line of MMC inverter station fails, MMC sends short-circuit current to the fault point. The output short-circuit current of MMC is about 1-2 times of the rated current under the action of current limiter of control system. According to the dynamic response characteristics of MMC converter station controller, the short-circuit current calculation formula of $\mathrm{AC}$ side output of $\mathrm{MMC}$ inverter station under $\mathrm{AC}$ grid fault can be derived.

When the $\mathrm{AC}$ line of $\mathrm{MMC}$ inverter station fails, the active power and reactive power transmitted by MMC decrease, the AC bus voltage $U_{s m}$ drops and the DC voltage $U_{d c}$ rises instantaneously. These factors will lead to the output current 
command value ivd and ivq increase of the outer loop controller. The active current command changed after the fault is Id1 and the reactive current command is iq1.

The output short-circuit current formula of MMC inverter station after fault is as follows:

$$
\left\{\begin{array}{l}
i_{a 1}(t)=I_{m} \cos \left(\omega t+\theta_{1}+\varphi\right) \\
i_{b 1}(t)=I_{m} \cos \left(\omega t+\theta_{1}-\frac{2 \pi}{3}+\varphi\right) \\
i_{c 1}(t)=I_{m} \cos \left(\omega t+\theta_{1}+\frac{2 \pi}{3}+\varphi\right)
\end{array}\right.
$$

where: $\phi=\arctan \left(i_{q 1}^{*} / i_{d 1}^{*}\right) ; I_{m}$ is the amplitude of fault current, $I_{m}=\sqrt{\left(i_{d 1}^{*}\right)^{2}+\left(i_{q 1}^{*}\right)^{2}}$, $\theta_{1}$ is the initial phase of phase a current.

When $I_{m}$ exceeds $I_{\text {lim }}$, the reference values of both active and reactive components will be limited. When the MMC current limiting control condition is reached, the shortcircuit current expression of MMC inverter station is as follows:

$$
\left\{\begin{array}{l}
i_{a 1}(t)=i_{\lim } \cos \left(\omega t+\theta_{1}+\varphi\right) \\
i_{b 1}(t)=i_{\lim } \cos \left(\omega t+\theta_{1}-\frac{2 \pi}{3}+\varphi\right) \\
i_{c 1}(t)=i_{\lim } \cos \left(\omega t+\theta_{1}+\frac{2 \pi}{3}+\varphi\right)
\end{array}\right.
$$

The above short-circuit current formula states that MMC is a current source with controlled amplitude. The amplitude of current source is determined by both active current command $i_{d 1}^{*}$ and reactive current command $i_{q 1}^{*}$. When the controller current limit $I_{\lim }$ is reached, the short-circuit current amplitude remains constant at $I_{\text {lim }}$; Short circuit current phase angle $\phi$ increases with the increase of reactive current command $i_{q 1}^{*}[14]$.

Since the MMC-HVDC rectifier station is equivalent to the active load for the sending end grid, the protection of AC lines on the rectifier side has nothing to do with the MMC characteristics, so the applicability analysis of three-stage current protection for $\mathrm{AC}$ distribution lines of MMC inverter station is carried out. Figure 8 shows the fault diagram of $\mathrm{AC}$ distribution network line of $\mathrm{MMC}$ inverter station, in which $\mathrm{MMC}$ is equivalent to current source. 


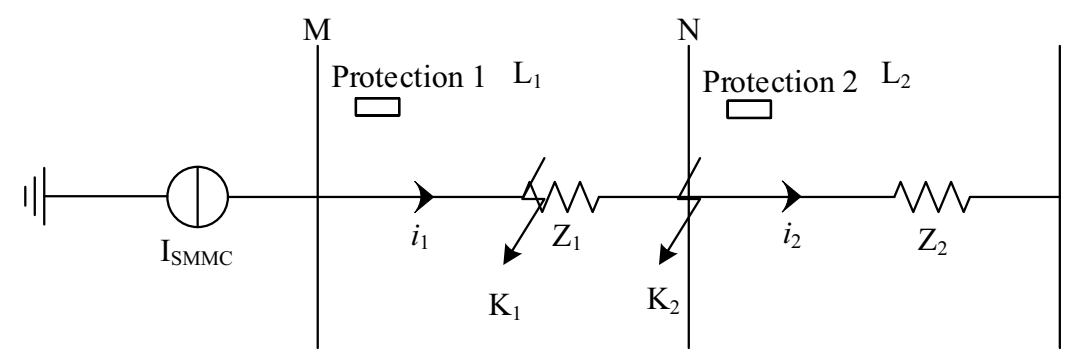

Figure 8. Fault diagram of distribution network of MMC inverter station.

According to the setting principle of three-stage current protection of traditional AC system:

The action current of protection 1 is as follows:

$$
\begin{gathered}
I_{\text {set. } 1}^{\mathrm{I}}=K_{\text {ret. } 1}^{\mathrm{I}} \frac{U}{Z_{s m}+Z_{1}} \\
I_{\text {set. } 1}^{\mathrm{II}}=K_{r e t .1}^{\mathrm{II}} K_{r e t .2}^{\mathrm{I}} \frac{U}{Z_{s m}+Z_{1}+Z_{2}} \\
I_{\text {set. } 1}^{\mathrm{III}}=\frac{K_{r e t .1}^{\mathrm{III}} K_{M \mathrm{~s}}}{K_{r e}} I_{L \cdot \max }
\end{gathered}
$$

where: $K_{\text {ret.1 }}^{\mathrm{I}}, K_{\text {ret. } 1}^{\mathrm{II}}$ and $K_{\text {ret.1 }}^{\mathrm{III}}$ are the reliability coefficients of current protection, taking $1.2 ; Z_{s m}$ is the equivalent impedance at the back side of MMC outlet bus; $K_{M \mathrm{~s}}$ is the self starting coefficient, taking $1.5 ; K_{r e}$ is the return coefficient of current relay, taking $0.85 ; I_{L \cdot \max }$ is the maximum load current that may appear on the line.

In the three-stage current protection, the protection range of current section $\mathrm{I}$ is required to be greater than $20 \%$ of the length of the line, and the protection range of current section II is required to be the full length of the line. The sensitivity of current section II protection is checked according to the ratio of the short circuit current of twophase short circuit at the end of the line to the setting value of section II under the minimum operation mode. This is feasible in the traditional power network, because in the traditional power network, the equivalent impedance of positive and negative sequence is basically equal, and the short circuit of two-phase short circuit is $\sqrt{3} / 2$ times of that of three-phase short circuit. However, when an asymmetric fault occurs in the AC line of the MMC inverter station, the MMC AC fault ride through strategy controls the negative sequence current in the short-circuit current and suppresses the negative sequence component to zero. The negative sequence equivalent network of the MMC converter station is an open circuit system with infinite resistance. In this case, the two-phase short-circuit current is no longer $\sqrt{3} / 2$ times of the three-phase shortcircuit current. Considering the influence of MMC AC fault ride through strategy on 
short-circuit current, the traditional current protection setting method is likely to need to be improved.

\section{RTDS Simulation Analysis}

In the RTDS simulation platform, the flexible AC/DC distribution network system model which supplies power to the passive network is built as shown in figure 1 . The $\mathrm{DC}$ system voltage is $\pm 10 \mathrm{kV}$, the voltage of AC system is $10 \mathrm{kV}$. The connection mode of converter transformer is DYn (grounded through $2 \mathrm{~K}$ high resistance). AC $10 \mathrm{kV}$ system is a small current grounding system, which is grounded through Z-type grounding transformer. AC distribution network load only considers constant power load, which is set to $1 \mathrm{MW}$, and its power factor is 0.85 . The length of DC cable is 8 $\mathrm{km}$, the AC lines L1and L2 are 4km, and the impedance parameter of unit length of the line is $z_{1}=0.17+j 0.3768 \Omega / \mathrm{km}$. The $U_{d c}^{*}$ of MMC control system is set to $20 \mathrm{kV}$, $Q^{*}$ is set to 0 Mvar, and the simulation system parameters are shown in table 1 .

Table 1. Simulation system parameters.

\begin{tabular}{ll}
\hline Parameter & Numerical value \\
\hline The module number $\mathrm{N}$ & 200 \\
Capacitance $\mathrm{C}_{0}$ & $40000 \mu \mathrm{F}$ \\
Submodule capacitance voltage & $0.1 \mathrm{KV}$ \\
The bridge arm inductance $\mathrm{L}_{0}$ & $0.01268 \mathrm{H}$ \\
MMC Nominal capacity & $6 \mathrm{MVA}$ \\
Flat wave reactor & $8 \mathrm{mH}$ \\
Rated rheological ratio & $10 \mathrm{KV} / 10 \mathrm{KV}$ \\
Rated rheological capacity & $10 \mathrm{MVA}$ \\
\hline
\end{tabular}

\subsection{Fault Simulation of Inverter Side under AC Fault Ride through Strategy}

The fault diagram of the flexible DC system is shown in figure 9. To verify the function of the designed AC fault ride through strategy, the $\mathrm{AC}$ bus of MMC inverter station is set to fail in $0.06 \mathrm{~s}$, and the fault lasts for $0.2 \mathrm{~s}$ before clearing. The simulation figure is shown in figures 10-15.

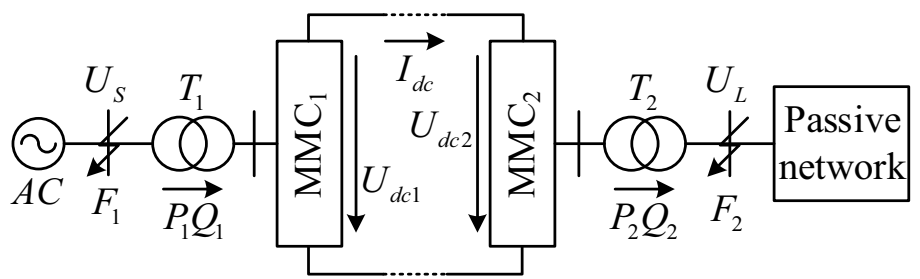

Figure 9. MMC-HVDC system fault diagram. 


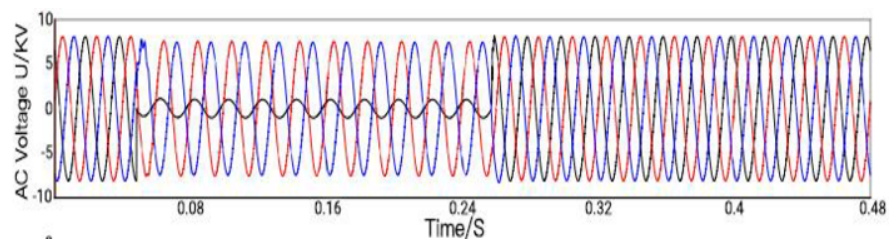

Figure 10. Fault voltage of single-phase ground short circuit AC distribution network.

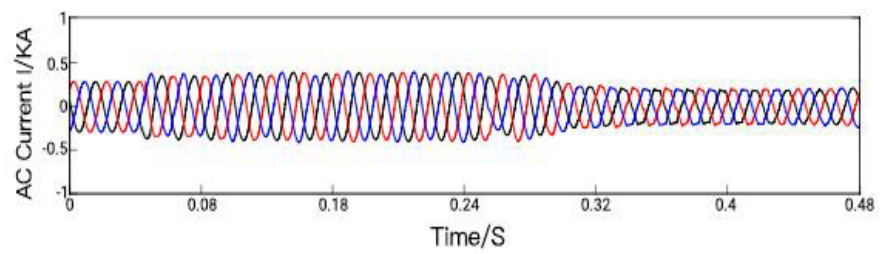

Figure 11. MMC valve side output fault current for single - phase ground short circuit.

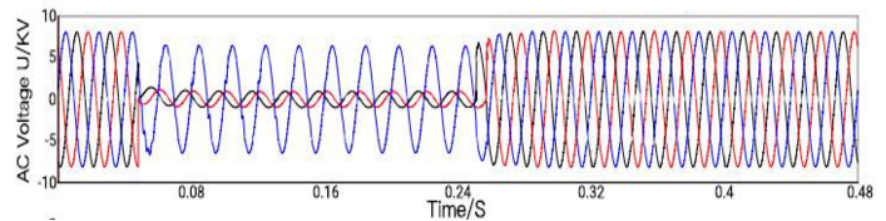

Figure 12. Fault voltage of two-phase ground short circuit AC distribution network.

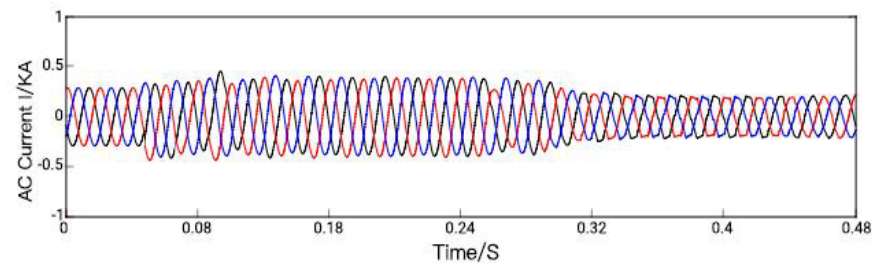

Figure 13. MMC valve side output fault current for two - phase ground short circuit.

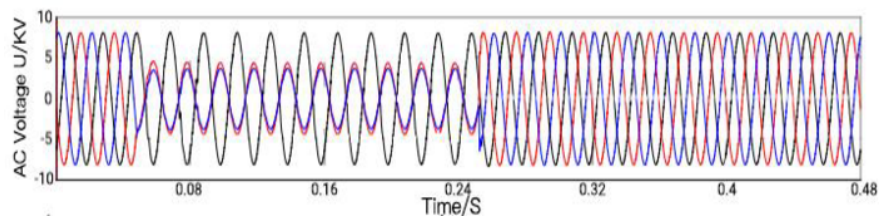

Figure 14. Fault voltage of two-phase short circuit AC distribution network.

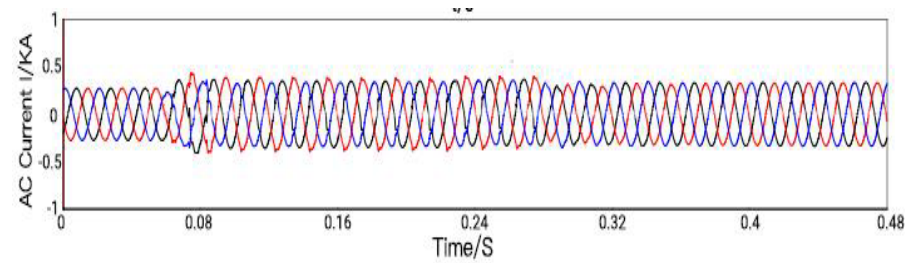

Figure 15. MMC valve side output fault current for two-phase short circuit. 
From the simulation waveform, it can be seen that when the AC bus of MMC inverter station has asymmetric fault, the fault current waveform output from MMC valve side presents three-phase symmetry under the strategy of AC fault crossing. The simulation results show that the negative current sequence component is effectively suppressed to 0 under the AC fault crossing strategy, and the function of the proposed strategy is realized.

\subsection{Applicability Analysis of Three-Stage Current Protection}

$10 \mathrm{kV}$ is a small current grounding system. This paper analyzes the applicability of three-stage current protection in the case of two-phase short circuit and three-phase short circuit.

\subsubsection{Setting Value of Three-Stage Current Protection}

According to the action logic of three-stage current protection, the logic control circuit of three-stage current protection is built on RTDS platform, which mainly includes current transformer, three-stage current judgment part and logic signal output part. In simulation, the amplitude of the fundamental frequency component of fault current is extracted by Fourier algorithm, and then the effective value of the fundamental wave is obtained. When the short circuit of line L1 occurs in three phases, the effective value of the basic wave of fault current flowing through protection 1 is $0.42 \mathrm{KA}$, so the setting value of current section $\mathrm{I}$ is $0.5 \mathrm{KA}$. The setting value of protection coordination between line L1 current section II and line L2 current section I protection is $0.46 \mathrm{KA}$, and the setting value of protection coordination with line L2 current section II is $0.375 \mathrm{KA}$. The maximum load current is $0.068 \mathrm{KA}$, and the protection setting value of section III of line L1 set according to the reliability coefficient 1.3 is $0.156 \mathrm{KA}$.

When the fault crossing strategy is not put into operation, the current detected by protection 1 when two-phase short circuit fault occurs at L1 end of line is $0.488 \mathrm{KA}$. At this time, the sensitivity of L1 current section II protection and L 2 current section I and section II protection are 1.06 and 1.3 respectively; When the fault crossing strategy is put into operation, the current detected by protection 1 when two-phase short circuit fault occurs at L1 end of line is $0.34 \mathrm{KA}$. At this time, the sensitivity of L1 current section II protection and L2 current section I and section II protection are 0.74 and 0.9 respectively.

\subsubsection{Analysis of Action Characteristics of Three-Stage Current Protection}

The input and non input of AC fault crossing strategy do not affect the judgment of current protection action performance in case of symmetrical fault. However, when asymmetric fault occurs, the input and non input of AC fault crossing strategy will change the amplitude of short circuit current output of asymmetric fault MMC, which may lead to the poor performance of current protection under the action of AC fault crossing strategy. Therefore, it is necessary to simulate and compare the current protection action in the case of asymmetric fault.

Two phase short circuit and three-phase short circuit fault occur in different positions of line $\mathrm{MN}$, and the fault time is $0.1 \mathrm{~s}$. considering the action time limit of current quick break protection and timed overcurrent protection, the fault duration is set to $5 \mathrm{~s}$. The action of protection 1 under different fault types is shown in tables 2 and 3. 
Table 2. Symmetrical fault protection action.

\begin{tabular}{lll}
\hline \multirow{2}{*}{ The fault types } & \multicolumn{2}{l}{ Fault protection action at different positions } \\
\cline { 2 - 3 } & I section & II section \\
\hline $\mathrm{MN} \mathrm{25 \%} \mathrm{f}_{\mathrm{ABC}}$ & Refused to action & Action \\
$\mathrm{MN} 50 \% \mathrm{f}_{\mathrm{ABC}}$ & Refused to action & Action \\
$\mathrm{MN}$ terminal $\mathrm{f}_{\mathrm{ABC}}$ & Refused to action & Action \\
\hline
\end{tabular}

Table 2 states that when three-phase short circuit fault occurs at $25 \%$ and $50 \%$ of the line, current section I refuses to operate, and current section I can not operate reliably to remove the fault, which can only be removed by current section II, which can protect the whole length of the line.

Table 3. Asymmetric fault protection action.

\begin{tabular}{lllll}
\hline \multirow{2}{*}{ The fault types } & \multicolumn{2}{l}{ Do not engage in a failover strategy } & \multicolumn{2}{l}{ Engage in a failover strategy } \\
\cline { 2 - 5 } & I section & II section & I section & II section \\
\hline $\mathrm{MN} 25 \% \mathrm{f}_{\mathrm{ABC}}$ & Refused to action & Action & Refused to action & Refused to action \\
$\mathrm{MN} 50 \% \mathrm{f}_{\mathrm{ABC}}$ & Refused to action & Action & Refused to action & Refused to action \\
$\mathrm{MN}$ terminal $\mathrm{f}_{\mathrm{ABC}}$ & Refused to action & Action & Refused to action & Refused to action \\
\hline
\end{tabular}

According to table 3, when AC fault crossing strategy is not put into operation, when two-phase short circuit fault occurs at $25 \%$ and $50 \%$ of the line, fault current includes positive sequence component and negative current sequence component. At this time, current section I does not act, and fault can only be removed by current section II, and current section II can protect the whole length of the line. When AC fault crossing strategy is put into operation, fault current only contains positive sequence component of current, while negative current sequence component is suppressed to 0, and short circuit current amplitude decreases, leading to rejection of current section II. Current section III can only be cut off by delay of current section III, but the delay of current section III is long, which is not conducive to timely fault removal.

\section{Conclusion}

The applicability of three-stage current protection of $\mathrm{AC}$ distribution network line in MMC inverter station of flexible AC DC distribution network is studied. Using the derived characteristics of MMC short circuit current, the following conclusions are drawn by combining the fault crossing strategy input and the three-stage current protection action under two conditions, input and no input:

(1) When the symmetrical fault occurs in the AC distribution network of MMC inverter station, the current I section will not move, and the fault can only be removed by current section II, and the current section II can protect the whole length of the line.

(2) When the AC distribution network line of MMC inverter station has asymmetric fault, the main current protection section I and section II are not operated under the action of AC fault crossing strategy, which can not guarantee the reliability of main protection action. Only the fault can be removed by the delay of the near backup protection current section III of the line. 
The above analysis results show that the three-stage current protection based on the fault current characteristics of pure $\mathrm{AC}$ system is no longer applicable. It is necessary to fully consider the characteristics of MMC short circuit current and the cooperative ideas of control and protection to construct the line protection suitable for the AC distribution network of MMC inverter station.

\section{References}

[1] Song Q 2013 Summary of research on intelligent DC distribution network Journal of Electrical Engineering of China 33 (25) 9-19.

[2] Qi Q 2020 Research status and development trend of smart distribution network flexible interconnection Power Grid Technology 44 (12) 4664-4676.

[3] Xiao L and Xu Z 2016 AC fault crossing strategy for MMC-HVDC transmitter power supply to passive networks Transactions of China Electrotechnical Society 31 (15) 89-98.

[4] Cai X H and Zhao C Y 2014 Control and protection strategy of MMC-HVDC system powered to passive network Proceedings of the CSEE 34 (3) 405-414.

[5] Li Y B 2019 Analysis of short-circuit current level mechanism of flexible DC transmission converter station Global Energy Internet 2 (6) 581-588.

[6] Bu G Q 2017 Study on mechanism of MMC influence on short-circuit current of three-phase shortcircuit fault in AC system Proceedings of the CSEE 37 (21).

[7] Guo M X 2020 Influence factors of flexible DC contribution short-circuit current and engineering algorithm error analysis Journal of Power Systems and Automation 36 (8) 1-18.

[8] Mao S R and Xu Z 2020 Effect of MMC on short-circuit current in AC system with short-circuit fault and its suppression strategy Electric Power Automation Equipment 40 (12) 5-36.

[9] Yi Y 2018 Characteristic analysis and calculation method of AC short-circuit current contribution in VDC transmission system High Voltage Technology 44 (7) 2773-2782.

[10] Tang G, Xu Z, et al. 2013 Design of multi-terminal flexible HVDC transmission control system based on modular multi-level converter High Voltage Technology 39 (11) 2773-2782.

[11] Guan M Y and Xu Z 2013 Modelling and control of MMC Type HVDC power transmission system for passive network Transactions of China Electrotechnical Society 28 (2) 255-263.

[12] Liang Y Y 2015 High performance control strategy of MMC-HVDC inverter station powered to passive network Power System Automation 39 (23) 119-164.

[13] Xu Z 2016 Flexible DC Transmission System (Machinery Industry Press).

[14] Xiao C 2020 Study on adaptability of AC side line relay protection in flexible HVDC transmission system Smart Power 48 (4) 1-8. 